\title{
Laparoscopic excision of splenic hydatid cyst
}

\author{
K I A Gharaibeh
}

\begin{abstract}
Hydatid disease of the spleen is a rare condition. The standard treatment is open total or partial splenectomy. Recently hand assisted laparoscopic total splenectomy for splenic hydatid cyst has been reported. A case is described of splenic hydatid cyst in a 45 year old man that was excised laparoscopically; the related literature is reviewed.

(Postgrad Med f 2001;77:195-196)
\end{abstract}

Keywords: hydatid disease; spleen; laparoscopy; Jordan

Hydatid disease is common in Jordan, the liver being the most common site, while the spleen is involved in $2.5 \%$ of the cases. ${ }^{1}$ Until the early 1970, open splenectomy was the standard procedure for splenic hydatid cysts. Since then, preservation of the spleen has been common practice and partial open splenectomy for hydatid cyst has been reported. ${ }^{2}$ With the introduction of laparoscopic surgery, hand assisted laparoscopic splenectomy for a hydatid cyst has been reported once, ${ }^{3}$ although for splenic non-parasitic cysts, laparoscopic partial splenectomy has been carried out. ${ }^{4}$ Since our patient was in favour of the laparoscopic approach and the location of the cyst in the lower pole, we decided to attempt to treat it laparoscopically.

\section{Case report}

A 45 year old man presented with a six week history of left upper quadrant heaviness. On examination the spleen was just palpable under the costal margin. Ultrasonography, chest radiography, and computed tomography revealed an $8 \times 12 \mathrm{~cm}$ cyst occupying the lower pole of the spleen (fig 1), but no involvement of the liver, kidney, and chest. Indirect haemagglutination test for hydatid diseases was negative. Despite that, the possibility of hydatid disease could not be excluded. The cyst in the lower pole was thought to be suitable for laparoscopic excision. Medications for treating anaphylactic reaction such as adrenaline (epinephrine), corticosteroids, $\mathrm{H}_{1}$ and $\mathrm{H}_{2}$ receptor antagonists were prepared in syringes ready for immediate use.

With the patient in the supine position, pneumoperitoneum using the open technique through the umbilicus was carried out with an intra-abdominal pressure of $10 \mathrm{~mm} \mathrm{Hg}$. The patient was then repositioned in reversed Trendlenberg with slight tilt to the right. Using a $30^{\circ}$ lens, the lower pole of the spleen was found to be adherent to the greater omentum. Three more ports were created: a $10 \mathrm{~mm}$ port just below and to left of the xiphoid cartilage, a $5 \mathrm{~mm}$ port in the left subcostal border in the anterior axillary line, and a $5 \mathrm{~mm}$ port parallel to the umbilicus in the left mid-clavicular line.

A small window was made in the adhesions with the lower pole, which showed the whitish characteristic appearance of the external wall of the hydatid cyst. A suction aspiration needle with a two way connection, one to a $100 \mathrm{ml}$ empty syringe and the other one to a $100 \mathrm{ml}$ syringe filled with cetrimide $0.5 \%$ solution, was introduced through the left subcostal $5 \mathrm{~mm}$ port. The cyst was punctured with the needle through the window that was created and suction was applied. Crystal clear fluid was aspirated, which was further evidence that the cyst was hydatid. About $60 \mathrm{ml}$ of the contents of the cyst were aspirated, cetrimide was then injected until the cyst was tense, and it was then left for 10 minutes. Then there was further aspiration of $100 \mathrm{ml}$ of the fluid in the cyst followed by cetrimide injection, which was left for a further 10 minutes, after which the cyst was evacuated and opened. A white membrane (the laminated membrane) then collapsed inside the lumen of the cyst. A cuffed glove, that was tied and divided at the junction between the fingers and the palm, was then introduced through the $10 \mathrm{~mm}$ epigastric trocar and used as a bag as that described by Patton et al. ${ }^{5}$ The membrane was introduced inside the glove bag, which was then brought out intact with the $10 \mathrm{~mm}$ trocar, then the trocar was reintroduced and the cyst was deroofed and inspected. No bleeding points or debris were seen. The greater omentum was used to fill the cavity and was stitched to the edges of the cavity with $2 / 0$ Vicryl (Ethicon, Edinburgh, UK). 12 F size suction drain was introduced through the midclavicular line port and positioned lateral to the lower pole of the spleen. Closure of the $10 \mathrm{~mm}$ facial layer was carried out using 0 Vicryl (Ethicon, Edinburgh, UK). The skin was closed with non-absorbable suture. The operation time was 145 minutes. Postoperative recovery was uneventful and the drain was

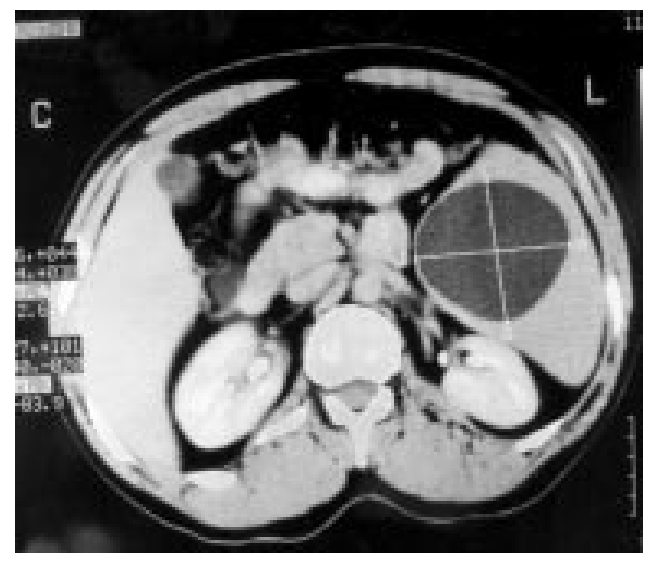

Figure 1 Computed tomography of the abdomen showing the splenic hydatid cyst. 


\section{Learning points}

- Although it is early, excision of a superficially located splenic hydatid cyst may be feasible laparoscopically.

- To minimise the incidence of leak and recurrence adjuvant therapy with albendazole is suggested.

removed after 24 hours. The patient was discharged on the third postoperative day.

Analysis of the aspirated fluid revealed small daughter cysts. Histology of the membrane showed a laminated acellular wall with fibrocollagenous tissue. Albendazole $400 \mathrm{mg}$ twice daily was started from the first postoperative day and continued for two months, during which his liver function tests and full blood count were normal. Ultrasonography was carried out six months later, which showed that the cyst became smaller in size with the omentum inside it. The patient was still well 13 months after surgery.

\section{Discussion}

Hydatid disease caused by Echinococcus granulosus is endemic in the Middle East. Involvement of the spleen is rare and in Jordan the incidence is $2.5 \%$ of cases. ${ }^{1}$ Parasitic cysts of the spleen are almost exclusively due to ecchinococcal disease, in endemic areas 50\%-80\% of splenic cysts are ecchinococcal.

Open splenectomy was the standard treatment for benign splenic disorders until the early 1970, when fatal postsplenectomy sepsis was widely recognised. Partial splenectomy was therefore introduced, initially for trauma and later for most benign splenic diseases, including non-parasitic cysts, ${ }^{7}$ and parasitic hydatid cysts. $^{2}$

In the laparoscopic era, laparoscopic splenectomy for various benign conditions was found to be feasible and superior to open splenectomy. ${ }^{8}$ This was followed by laparoscopic partial splenectomy for non-parasitic cysts. $^{4}$

In one report 76 patients underwent laparoscopic management of their hydatid liver cysts and almost all of them were superficial. ${ }^{9}$ Laparoscopic management of splenic hydatid cysts has not been reported so far, apart from one case report of total splenectomy using hand assisted laparoscopic technique using an $8 \mathrm{~cm}$ incision to extract the spleen. ${ }^{3}$ The reluctance to perform laparoscopic surgery for hydatid disease is probably because of the concern of spillage of the fluid into the peritoneal cavity, with the possibility of anaphylactic reaction and recurrence. ${ }^{10}$ Spillage of protoscolexrich fluid during surgery occurs in 5\%-10\% of cases ${ }^{11}$ despite all precautions taken to prevent it, but this does not necessarily lead to dissemination. ${ }^{12}$ Only one case of anaphylactic reaction complicating laparoscopic treatment of hydatid cysts of the liver has been reported and was due to inadvertently advancing the aspiration needle into the liver parenchyma. ${ }^{13}$ Recurrence after surgery was reported in up to $18 \%$ of cases, ${ }^{14}$ which may be due to incomplete removal, spillage, or growth of small occult cysts that were missed initially. ${ }^{15}$

Medical treatment with albendazole has been shown to be effective in inoperable cases, in patients who refuse surgery, as an adjuvant therapy preoperatively, perioperatively, or postoperatively if spillage occurs to minimise recurrence. ${ }^{15-17}$ In our case we decided preoperatively to use albendazole (if the cyst was found to be a hydatid one) because the spleen is a rare site and the possibility of hydatidosis in other parts of the body could not be completely eliminated, despite the normal chest radiography, ultrasound, and computed tomography. The possibility of occult perioperative leak was also considered another indication for medical therapy. ${ }^{15}$

In conclusion, we feel that hydatid disease of the spleen can be successfully treated laparoscopically, provided that it is prominent on the surface and that adequate precautions are taken to avoid or minimise leak. We also feel that to combat the high recurrence, adjuvant medical therapy should be carried out postoperatively in all sites of hydatid cyst surgery.

1 Amr SS, Amr ZS, Jitawi S, et al. Hydatidosis in Jordan: an epidemiological study of 306 cases. Ann Trop Med Parasitol 1994;88:623-7.

2 Manouras AJ, Nikolaou CC, Katergiannakis VA, et al. Spleen-sparing surgical treatment for echinococcosis of the spleen. Br F Surg 1997;84:1162.

3 Ballaux KEW, Himpens JM, Leman G, et al. Hand-assisted laparoscopic splenectomy for hydatid cyst. Surg Endosc 1997;11:942-3.

4 Sellers GJ, Starker PM. Laparoscopic treatment of a benign splenic cyst. Surg Endosc 1997;11:766-8.

5 Patton JT, Jorgensen JO, Imrie CW. Specimen retrieval in laparoscopic cholecystectomy. Br F Surg 1997;84:957.

6 Gidaro GS. [Cystic splenic disease of surgical interest]. $G$ Chir 1997;18:555-9.

7 Sagar PM, McMahon MJ. Partial splenectomy for splenic cysts. Br F Surg 1988;75:488.

8 Brunt LM, Langer JC, Quasebarth MA, et al. Comparative analysis of laparoscopic versus open splenectomy. Am $\mathcal{F}$ Surg 1996;172:596-601.

9 Sayek I, Cakmakci M. [Laparoscopic management of echinococcal cysts of the liver]. Zentralbl Chir 1999;124: 1143-6.

10 Katkhouda N, Hurwitz M, Gugenheim J, et al. Laparoscopic management of benign, solid and cystic lesions of the liver. Ann Surg 1999;229:460-6.

11 Mottaghian H, Saidi F. Postoperative recurrence of hydatid disease. Br F Surg 1978;65:237-42.

12 El Mufti M. Clinical echinococcosis. In: El-Mufti M, ed. Surgical management of hydatid disease. London: Butterworths, 1989: 27-30.

13 Khoury G, Jabbour-Khoury S, Soueidi A, et al. Anaphylactic shock complicating laparoscopic treatment of hydatid cysts of the liver. Surg Endosc 1998;12:452-4.

14 Mentes A,Yüzer Y, Ozbal O, et al. Omentoplasty versus introflexion for hydatid liver cysts. $\mathcal{F}$ R Coll Surg Edinb 1993; introflexi $38: 82-5$.

15 Karavias DD, Vagianos CE, Bouboulis N, et al. Improved techniques in the surgical treatment of hepatic hydatidosis. Surg Gynecol Obstet 1992;174:176-80.

16 Teggi A, Lastilla MG, De Rosa F. Therapy of human hydatid disease with mebendazole and albendazole. Antimicrob Agents Chemother 1993;37:1679-84.

17 Stamatakis J. Hepatic hydatid disease. In: Johnson CD, Taylor I, eds. Recent advances in surgery (17). London: Churchill Livingstone, 1994: 35-48. 